\title{
7 Digital Libraries and their Communities
}

\author{
Karen Calhoun \\ Cornell University Library (retired) \\ ksc10@cornell.edu
}

Note: This is a preprint of a chapter whose final and definitive form was co-published in Exploring Digital Libraries: Foundations, Practice, Prospects by Facet Publishing (2014) and ALA Neal-Schuman (2014).

\section{Overview}

What sets thriving, long-lived digital libraries apart from those that attract only modest attention or have faded into memory? Why have some digital libraries had a distinctive impact on the communities they were built to serve, while others are more or less ignored? This chapter examines these issues. It builds on table 2.1's descriptions of a sample of working digital libraries that have been successful since they began in the first decade of digital libraries (19912001). It also takes up themes from chapter 6 , which examines the ways that digital libraries produce, or could produce value for the communities they serve.

\section{Approach}

This chapter uses the results of interviews with nine well-known digital library experts (listed at the beginning of the book) to approach the question of what makes digital libraries successful in their communities. Interweaving the results of the interviews and the findings of other digital library researchers and practitioners, the chapter examines the distinguishing characteristics leading to long-term viability.

\section{Successful, sustainable digital libraries}

When digital libraries were beginning two decades ago, the web was characterized by fairly passive, read-only sites. As the web evolved into a more social space, users came to expect 
more interactive sites. It stands to reason that when users approach digital libraries, they bring their expectations and experiences from other sites with them. Accordingly, this chapter begins with an analysis from the domain of online communities, which for the purpose of this discussion, are network-based spaces in which participants communicate and interact, share and contribute content, and build or maintain relationships.

\section{The study of online communities}

Alicia Iriberri and Gondy Leroy (2009) offer a life-cycle perspective on online community success. Their often-cited analysis focuses on the evolution of online communities and identifying success factors in each evolutionary stage: inception, creation, growth and maturity (or death). They take the characteristics of several types of online communities into account: support, interest-based, knowledge, gaming, and transactions-based communities.

Iriberri and Leroy's life-cycle model is based upon a comprehensive review of research and practice in the emerging field of online communities-a body of literature that is highly multidisciplinary and growing fast. Unlike much of what has been written, their approach to modeling what attracts and maintains an online community is complex and contextual. Their model is a multilayered synthesis that interweaves social, behavioral, psychological, business, organizational, and technological elements. Iriberri and Leroy's article offers full explanations of the life-cycle stages and success factors for online communities, and a reading is well worth the time.

Figure 7.1 is an attempt to briefly summarize and tailor Iriberri and Leroy's life-cycle success factors to digital libraries. The quadrants of the circle contain the life-cycle stages (clockwise from the upper left quadrant) and the text boxes contain key success factors for that stage. 


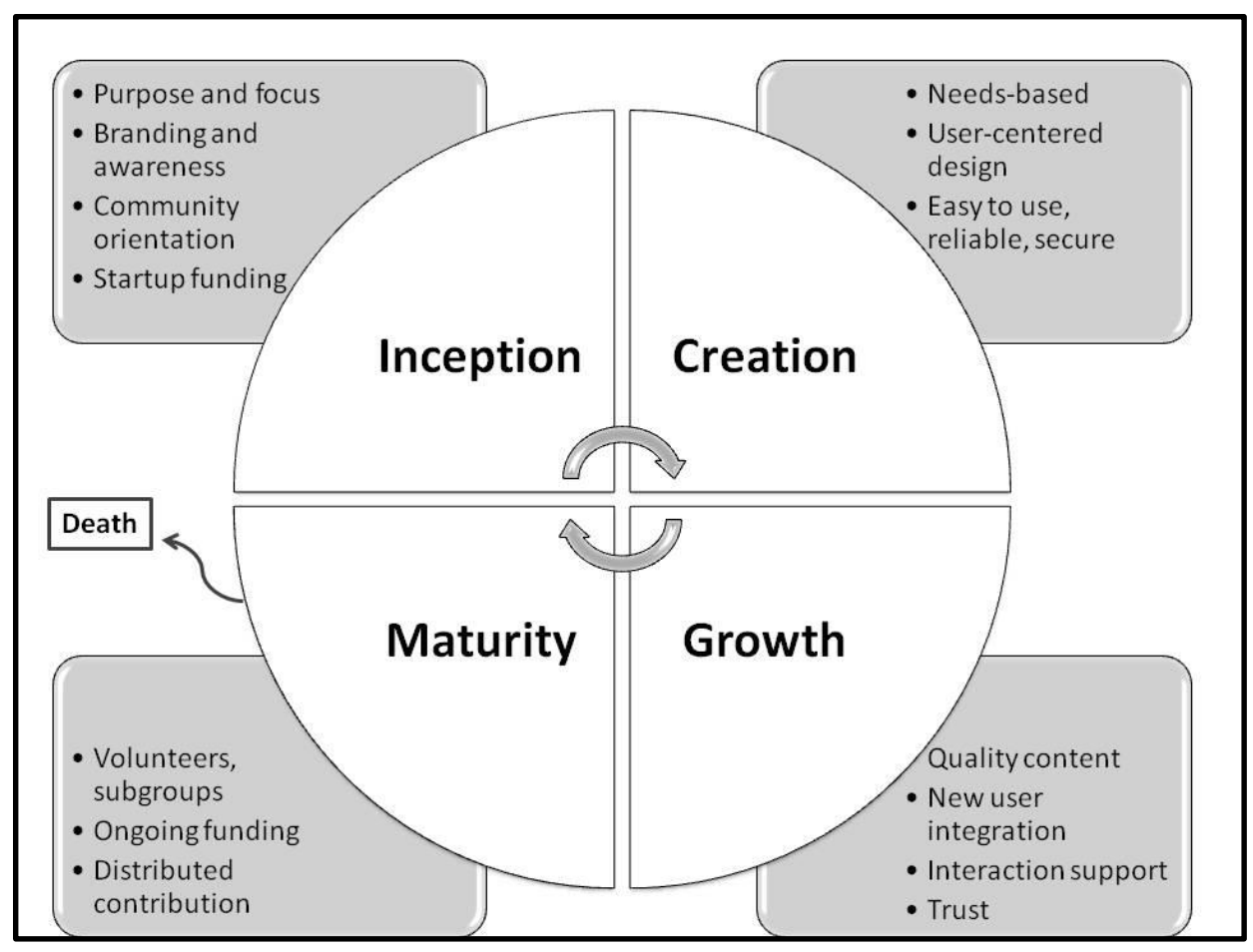

Figure 7.1 Life cycle model of success factors for digital libraries in social environments

The purpose of presenting a figure adapted from Iriberri and Leroy's ideas is not to suggest that digital libraries are online communities (although some can be). Instead the life cycle model can provide a frame for considering digital libraries in social environments.

\section{Related work in the digital library domain}

The idea of considering digital libraries in the context of social, community environments is not new. The report of an early NSF-sponsored workshop on the social aspects of digital libraries (Borgman et al. 1996) framed digital libraries in the context of social systems. Intriguingly, although it was written over 15 years ago, the report's illustration of the information life cycle in the art world (defined as a distributed community with myriad participants and groups playing different roles) seems quite familiar in today's context, in which the social web influences crosscommunity interactions, knowledge creation, communication and distribution. Along these lines 
and as discussed in chapter 6, Van House (2003) has defined digital libraries as boundary objects (entities that link dispersed communities together).

\section{What contributes to lasting digital libraries?}

The first question in the interviews conducted with digital library experts had to do with the traits of successful, sustainable digital libraries. Interview responses resonated with many of the success factors included in Iriberri and Leroy's life-cycle model. The following subsections focus on the success factors that were highly characteristic of interview responses. These were: purpose and focus; branding and awareness; community and needs orientation; user-centered design, ease of use and reliability; quality content; and funding and sustainability. Several of the success factors pertain to the inception stage, some to the creation stage, one to the growth stage, and one to the maturity stage.

\section{Inception: Purpose and focus}

\section{Commitment, engagement, mission}

Responses from the interviews suggest that successful digital libraries grow out of the communities for which they are intended, based on a purpose or purposes articulated within that community. Digital libraries that thrive are backed by passionate, committed builders on the one hand, and enthusiastic, vested community participants on the other. Alignment and focus around a clear, compelling mission for the digital library appear to be significant indicators of future success. A mission is the task or purpose for which an organization, group, or initiative exists. For example, with respect to table 2.1's five digital libraries built by national libraries (Trove, Gallica, American Memory, Papers Past and Sound Archive), there is a great deal of clarity, collaboration and commitment apparent around the mission, characteristic of national libraries, to:

- build and preserve a national collection reflecting cultural heritage and other fields 
- make it available in the national interest to both current and future researchers. and

- carry forward this mandate in the digital age

\section{Needs assessment}

Several interviewees also noted that the builders of successful digital libraries have tended to test and validate their assumptions about the purpose and focus of the digital library, including the

- needs the digital library addresses

- appeal of its content, and

- characteristics, expectations and work practices of the intended audience(s)

One interviewee, speaking of the major end-user test that preceded the building of American Memory, noted that "they initially thought the primary audience was professors and others in university settings. Actually, the audience turned out to be grade school and high school teachers."

Just as needs and audiences can shift, the appeal of digital library content can change over time. Alternatives can appear for digital content that was unique at the inception of the digital library and naturally such changes in conditions have an impact on the ability to appropriately balance a digital library's audience, collections and technologies.

\section{Community orientation}

A few interviewees noted the importance of the builders' being members of the intended audience for the digital library. For example, Paul Ginsparg, the person who started arXiv.org, is a highly respected physicist, and physics is one of the disciplines served by the arXiv. The 
vision, determination and commitment of highly visible, credible leaders are important factors in the digital library's success.

Other examples include digital library founders Michael Hart (Project Gutenberg) and Brewster Kahle (Internet Archive). In Hart's case, he was an author and innovator, passionate about books and literacy, and an unstoppable man of the people, whose vision of freely available ebooks was able to inspire volunteers and attract donations to make Gutenberg a success. Kahle was already an accomplished computer engineer and web entrepreneur when he founded the Internet Archive in 1996. Remarking on the Internet Archive, Carr $(2009,62)$ observes that "the quantity of electronic information that Kahle has preserved in the last decade is mind-bogglingly large." Like Kahle and Hart, numerous individuals provided remarkable leadership during the first decade of digital library research and practice.

\section{Inception: Branding and awareness}

Interviewees noted that successfully communicating the identity, intent, and nature of a digital library—in a way that resonates with its target audiences_-increases the likelihood of the digital library's take up and use. Although most digital library builders would not use the term, this activity is called "branding." Branding refers to the way intended audiences think about, identify and differentiate products, services, organizations and places. An example of successful branding is Starbucks, well known for its coffee and service.

The best brands capture and communicate the core values of the intended audiences. Keller (2000) provides a strong and readable introduction to product brands and branding; Berry (2000) explains service branding. Types of organizations and places can have brands too. Cathy De Rosa and her team determined, for example, that the library "brand" is books (2010, 
38-39). As for places, consider the association of Paris with the phrase "city of light," or the familiar brand "I Love New York."

\section{Some digital library brands}

Those who build and manage digital libraries do not tend to think of themselves as marketing or branding their collections or services. Nevertheless, in practice, successful digital library builders do describe their digital libraries in ways that attempt to capture their core value to the communities they serve. Not too many digital library builders brand their services. Among those who do, some examples are:

- Europeana 1914-1918: "Your family history of World War One"

- Europeana: "think culture"

- The British Library's EThOS: "opening access to UK theses"

- FamilySearch: "ancestors remembered"

- Internet Archive: "universal access to all knowledge"

- Gallica: "Une bibliothèque patrimoniale et encyclopédique" (heritage and encyclopedic library)

- HAL-INRIA: "inventeurs du monde numériques" (inventors of the digital world)

- JSTOR: "light up your mind. Scholarly journals, primary sources, and now books!"

- Mendeley: "simplify your research workflow"

- Project Gutenberg: "the first producer of free ebooks"

\section{Achieving awareness}

Achieving high awareness of a digital library among its intended audiences is another success factor. Interviewees noted a number of paths to high awareness and usage: 
- The builders are associated with a destination site that is recognized and well-respected by its target audiences (for example, PubMed Central)

- The digital library is unique in some way and there are few or no substitutes for its content (for example, Perseus, perseus.tufts.edu)

- The digital library site's content is made highly visible through search engine crawling (Google and/or Google Scholar), or by being embedded in or linked from other high traffic sites

- The materials on the site are freely available to all (open access)

\section{Discoverability}

Being discoverable in major search engines and/or other high traffic sites on the web is an enormous boost to the visibility of a digital library and a major factor in determining how much it is used. Embedding or linking from high traffic sites can also raise awareness and usage. Chapter 10 discusses the impressive results of embedding digital library images in "The Commons" on Flickr. Several interviewees mentioned a new strategy for greatly increasing the awareness of valuable digital library content-linking from Wikipedia articles, as described by Proffitt and Snyder (2012). Snyder, who works in the Archives of American Art (aaa.si.edu) at the Smithsonian, reported that she and colleagues became interested in working with Wikipedia, which receives nearly half a million unique visitors a month, to help the Archives reach as many users as possible. Wikipedia has greatly boosted the visibility of some of the Archive's images, which were uploaded to the Wikimedia Commons. Wikipedia has also become the single biggest referrer of web traffic to the Archives of American Art. 


\section{Creation: Community and needs orientation}

\section{The risks of "push" initiatives}

Interviewees also responded to the question of what makes digital libraries fail. Several mentioned projects characterized as "push" initiatives. The builders moved through the inception and creation stages with a "build it and they will come" attitude instead of a clear understanding of their intended audience(s) and the purposes with which these audiences would enthusiastically engage. Worse, the builders began with incorrect assumptions and a vague, untested value proposition (the benefits that users can expect to experience). Interviewees also pointed to the high risk of failure associated with digital library projects that were begun:

1. with general frameworks (rather than defining a framework by working directly with the intended audience or audiences), or

2. as academic exercises without a clear strategy or intent to build a lasting service

\section{Digital libraries as community centers}

The results of the interviews suggest additional dimensions to successful digital libraries in their communities: the digital library is (1) valued and understood by the communities being served; (2) easy to use, with low barriers to getting started; and (3) in close alignment with those communities' needs and how they work or want to work (or play). Table 7.1 provides some examples of successfully building an active community around a digital library. 
Table 7.1. Aligning digital libraries with community needs and practices: some examples

\begin{tabular}{|l|l|}
\hline National Library of Australia (Trove) & $\begin{array}{l}\text { The NLA made a commitment "to simplify the } \\
\text { complex digital landscape and to ensure that } \\
\text { the various services are interoperable" } \\
\text { (Cathro 2006, 5). The newspapers service is } \\
\text { an iconic example of successful } \\
\text { crowdsourcing (Holley 2010a) }\end{array}$ \\
\hline Bibliothèque nationale de France (Gallica) & $\begin{array}{l}\text { The BnF developed a digital library of cultural } \\
\text { heritage materials based on the needs of a } \\
\text { remote public, a new kind of researcher } \\
\text { (different from classical library users or } \\
\text { professional researchers), and new ways of } \\
\text { reading and understanding texts (Assadi et al. } \\
\text { 2003) }\end{array}$ \\
\hline International Children's Digital Library & $\begin{array}{l}\text { The ICDL designed and tested its digital } \\
\text { library through a process of remarkable } \\
\text { collaboration with a team of children (Druin } \\
\text { 2005) }\end{array}$ \\
\hline Social Science Research Network (ssrn.com) & $\begin{array}{l}\text { SSRN, the world's top-ranked repository } \\
\text { (repositories.webometrics.info), was co- } \\
\text { founded by Wayne Marr and Michael Jensen } \\
\text { in 1994. Jensen, a former Harvard Business } \\
\text { School professor, describes SSRN as a } \\
\text { scholarly "collaborative" providing services for } \\
\text { both authors and readers, opportunities for } \\
\text { peer interaction and participation, and early } \\
\text { distribution of research results. SSRN } \\
\text { contains a critical mass of highly discoverable } \\
\text { papers on a trusted site widely perceived as } \\
\text { dependable and highly beneficial to scholars } \\
\text { (Ricciardi 2007; Bray, Vizthum and Konsynski } \\
2008 ; \text { Jensen 2012). }\end{array}$ \\
\hline
\end{tabular}

A recent success in building an active community around a digital library is Europeana 19141918 (europeana1914-1918.eu), a highly interactive site where people can connect their stories and memorabilia with the holdings of libraries, museums and archives across Europe. Wilson (2012, 529-531) discusses Europeana 1914-1918 in his article on how new, more social methods for digital curation, which he calls digital "co-curation," can closely engage citizens with their countries' histories. 
Whether community members directly contribute to a digital library or not, buy-in from, and engagement with the community that gathers around the service is important. Cory Lampert and Jason Vaughan $(2009,123)$ gleaned the factors of a successful digitization program from a survey they administered of ARL libraries. The learned that faculty collaboration, interest and faculty partnerships were among the top factors leading to successful digital library programs in the responding research libraries.

\section{User-centered design}

The NSF-funded National Science Digital Library (NSDL) offers a particularly focused window into what has worked for digital libraries for educational communities. The NSDL's aim has been to substantially contribute to science, mathematics, engineering and technology education. The program, which began in 2000 with US $\$ 13.5$ million in grants for six projects, was intended to create openly accessible digital libraries serving the needs of learners from K-12 to higher education to life-long (Zia 2000; Arms et al. 2002).

Educational digital libraries sometimes stand alone (for example matdl.org for the materials sciences); they are sometimes components of larger portals or social sites (for example Math Tools, part of mathforum.org at Drexel; or Teach the Earth, part of serc.carleton.edu, discussed below); and sometimes they are explicitly designed as "landing pages" for searches referred from Google. A close partner of NSDL, the Digital Library for Earth Science Education (DLESE) provides a high-quality digital resource collection selected by geoscientists and educators working together (Marlino et al. 2001; Sumner 2010). Educational digital libraries can also integrate or interoperate with learning management systems (for example, merlot.org, a digital library of peer-reviewed materials supporting online learning, is accessible from BlackBoard). 


\section{Understanding the context of use}

Mimi Recker (Recker, Dorward and Nelson 2004, Recker 2006) participated in the NSDL projects and made a number of contributions to understanding how teachers find, access and use educational digital libraries and other learning resources, as did Mardis (2009) several years later. Writing of the early NSDL projects, Recker noted "missing ... is a deep characterization and understanding of learning environments, and how digital learning resources may fit into such contexts" $(2004,94)$. Recker and her colleagues at Utah State University studied the needs and behaviors of teachers. What they learned echoes Iriberri and Leroy's findings on what makes online communities successful. Manduca and others (2005; 2006) wrote two key articles based on their experiences with another NSDL project, the Starting Point Digital Library, which is now part of the Science Education Resource Center at Carleton College (serc.carleton.edu). These articles are well worth consulting, as they document the breakthroughs in the team's understanding of how to build successful digital libraries in social environments.

The insights gained into the practices, behaviors and preferences of their audiences led NSDL researchers and implementers to extend their efforts beyond collections to fully support online communities of educators. Manduca and her team noted "a successful digital library is as much a social process as a technical problem [that] ... requires creation of a culture that fosters contribution to and use of the library" (2006, under "Created by Partners"). As a result she and her team turned away from a traditional digital library interface, where the main service is distributed search across heterogeneous content. Instead they successfully introduced a social environment reflecting educator needs and the way that educators approach the site (from a variety of points on the network). Their digital library provides not just content, but a robust source of educator expertise. The new approach has been effective: as of the time of this 
writing, the Science Education Resource Center gets between 60,000 and 100,000 unique visitors per month (figures cover US only).

\section{Moving targets}

The NSDL was an ambitious national-level initiative with generous funding that spawned many projects, from which digital library researchers and practitioners learned a great deal about digital libraries and their communities. The massive disruption created over the last decade in the teaching and learning community by the rise of distance education, virtual learning environments (VLEs; web-based learning environments and systems that provide virtual access to classes, tests and other educational resources and enable interaction between teachers and students), and most recently, MOOCs (massive open online courses) has meant that digital library researchers and practitioners have been attempting to hit rapidly moving targets in the domain of web-based teaching and learning.

\section{Digital Public Library of America (DPLA)}

The Digital Public Library of America (DPLA) is a new initiative at the time of this writing. It launched in April 2013. The DPLA has a grand vision: to build "a large-scale digital public library that will make the cultural and scientific record available to all" (Peek 2012). As the DPLA rolls out over the next few years, it will be interesting to observe if its builders will take advantage of what the NSDL project teams learned about building active communities around digital libraries. The forecast is favorable: at the time of this writing, Dan Cohen, a history professor, director of the Center for History and New Media (CHNM), and a leading digital humanities scholar, has just been appointed founding executive director of the DPLA (Cohen 2013; Enis 2013). 


\section{Creation: User-centered design, ease of use and reliability}

Interviewees noted the importance to digital library success of ease of use, reliability and usercentered design (a philosophy and process for designing interactive systems in which the needs and practices of end users receive extensive attention; sometimes called human-centered design). They pointed to failed projects plagued by technical problems; projects that took too long; and early digital libraries that were built in unhelpful or dead-end ways, requiring significant investment in upgrades-investment funds that are often not found, and so the digital library languishes and eventually fades away.

\section{Usability and usefulness}

From a life-cycle perspective, technological components take center stage during digital library creation, but they remain critical success factors throughout the growth and maturity stages of community-centered digital libraries. Iriberri and Leroy note that different technological features take priority depending on the online community's evolutionary stage: "each stage requires different tools, features, mechanisms, technologies, and management activities. Developers have to identify the needs in each stage and add the right technology components..." $(2009,15)$.

Studies of success factors in the digital library literature often examine ease of use, interface design and access issues. Buchanan and Salako (2009) point out that most digital library studies investigate usability. Jakob Nielsen, an expert in web interface design, defines "usability" as "a quality attribute that assesses how easy user interfaces are to use" (www.nngroup.com/articles/usability-101-introduction-to-usability). He points out that interfaces can be usable without being useful, and the best interface will not make up for the absence of features supporting what the user wants to accomplish. Buchanan and Salako cast their net beyond usability; they compile an integrated measurement framework based on an extensive review of the relevant literature on the topics of usability and usefulness. Table 7.2 summaries 
these two key components in Buchanan and Salako's measurement framework. The table and text in their article contains considerably more detail, including definitions of each attribute.

\section{Table 7.2 Key Technological Success Factors}

\begin{tabular}{|l|l|}
\hline Success Factor & Attributes \\
\hline Usability & $\begin{array}{l}\text { Effectiveness, efficiency, aesthetic appearance, } \\
\text { terminology, navigation, and learnability }\end{array}$ \\
\hline Usefulness & Relevance, reliability, and currency \\
\hline
\end{tabular}

\section{Community partnerships}

As for user-centered design of digital libraries, Christine Borgman $(2009,46)$ crystallizes her two decades of experience with digital library and cyberinfrastructure research quite powerfully when she says "community partnerships in design are essential." While the application of usercentered design techniques in digital libraries dates back to the mid-1990s (Van House et al. 1996), experience suggests there were many projects in which the builders built, but the communities did not come. It is difficult to quantify how many, since the literature tends to be a poor source for learning about projects that failed.

Lage and others (2011) report on their careful work to identify researchers on their campus who are receptive toward library involvement in data curation (the management and preservation of digital data over the long term). Their intent is to understand researcher work practices and preferences at the design (inception) stage, so that effective partnerships between the library and scientists can be strategically developed. Somerville and Brar (2009) provide a thorough analysis of involving students in the digital library inception and creation stages. They describe a user-centered design process that recalled interviewees' comments about digital libraries' needing to "solve problems that users want solved" (rather than problems that builders think need to be solved). 


\section{Defining audiences}

Chern Li Liew, in an article evaluating the people and organizational aspects of a decade of digital library literature, noted that user-centeredness and user needs assessment appear among the topics being dealt with more frequently in digital library research since 2005 (2009, 253-254). Unfortunately, this trend appears to be weaker in ARL library special collections and digitization work: a key finding of an Ithaka study published at the time of this writing was that "investments in understanding the needs of the audience [for a digitized collection] are quite low" (Maron and Pickle 2013, 2).

\section{System performance and reliability}

System stability, reliability, adequate performance, an effective access rights structure and (depending on the type of digital library), technical components supporting security and privacy are also essential success factors. In addition, across the various stages of a digital library's life, a number of other technical tools may become essential, such as machine-to-machine services, or (depending on the digital library) tools supporting user interaction or personalization, recommending, commenting, user contribution, facilitation/moderation or volunteerism.

\section{Growth: Quality content}

Interviewees pointed out that what seems to drive success is the distinctiveness of the digital library's content for a particular community; the digital library is perceived by its users as a hub for a certain type of content that is essential to their shared interests. What seems to matter is the presence of a critical mass of content for the target audience(s). A glance through the descriptions of the digital libraries in table 2.1 reveals that the size of a digital library collection may not by itself be a primary factor for success: some are relatively large (e.g., Trove and the Internet Archive of websites) and some relatively small (e.g., the International Children's Digital 
Library and Project Gutenberg). Iriberri and Leroy's success factors for online communities include high-quality, up-to-date and legitimized content as critical during the growth stage; they also point to lack of quality content and infrequent contributions as symptoms of a dying community $(2009,11: 21-11: 25)$.

\section{Maturity: Funding and sustainability}

With the brevity bred of long experience, William Arms remarked, "financial sustainability is the Achilles heel of digital libraries" (Arms, Calimlim and Walle 2009). It is perhaps not surprising, then, that the digital library experts interviewed for this chapter most frequently pointed to the lack of sustainable funding as the reason for digital library failure. They pointed to another reason, associated with the lack of ongoing funding: a lack of clarity around who has ongoing responsibility for a digital library.

\section{Initial funding}

Government, international agency, foundation, private sector, institutional, and individual funding sources all played a part in getting digital libraries started. In many cases, the funding was temporary (see for example Griffin 2005). Many early projects were funded principally for research and prototype building - there was little or no intention to support large-scale implementations and ongoing services. Bill Arms and his co-authors, continuing their comments on the difficulties of financial sustainability for digital libraries, notes "while it is comparatively easy to raise money for innovation, few organizations have long-term funding to maintain expensive collections and services" (2009, under "Lesson Two").

\section{Challenges of ongoing funding}

A digital library initiative can be successful in every other way, but still have difficulties with financial sustainability. The following cases illustrate this conundrum: 
- Ricky Erway's white paper (2008) on the fate of the RLG Cultural Materials Alliance, which was discontinued, is an interesting case study of a digital library project's attempt to become financially self-sustaining in the real world of supply and demand on the web.

- DSpace has had a tremendous impact supporting open access repositories. MIT's final report to the Mellon Foundation, which with Hewlett Packard (HP) financed the initial development of DSpace (Barton and Harford Walker 2002), provides a case study. The report illustrates the challenges of moving from start-up grant support to reliance on a business mode/ that will continually cover the initiative's operating costs and also fund future development.

- If arXiv.org were assessed with this chapter's success factors, it would be deemed a thriving enterprise by nearly all measures (see Oya Rieger 2011, under "arXiv Sustainability Initiative"). The exception to its success is ongoing funding, which has been an issue for some years. "Who is responsible for the arXiv?" became an increasingly pressing question for Cornell University Library, which has supported the arXiv since the end of federal grant funding in 2001. In 2010, Cornell invited pledges to an interim voluntary contribution model. Further planning (Rieger 2012) led to the development of a new membership model, slated for launch in 2013.

\section{Succeeding at sustainability}

Maron, Smith and Loy (2009, 2-3), reporting on a set of Ithaka case studies, list the following factors that contribute to digital library sustainability:

- Dedicated and entrepreneurial leadership

- A clear value proposition

- Minimizing direct costs (costs directly associated with providing the digital library as a service; an example would be labor costs)

- Developing diverse sources of revenue 
- Clear accountability and metrics for financial and mission-related success

The Ithaka case studies can help digital library builders and managers understand the factors associated with various models for sustainability. The digital collections discussed in the 12 case studies represent work done in the UK, US, Germany, France and Egypt. The analysis uncovered a number of strategies for achieving sustainability, both financial and nonfinancial; table 7.3 lists these.

The strategies laid out in table 7.3 are further enriched by an article by Alma Swan, which includes a list of five operational models for sustaining digital repositories: institutional, public, community, subscription and commercial (Swan 2008, figure 2). Ricky Erway's profiles of seven highly successful subject-based repositories $(2012,16)$ provide another lens on how these types of digital libraries are financially sustained. 
Table 7.3 Strategies for sustainability (adapted from Maron, Smith and Loy 2009)

\begin{tabular}{|c|c|}
\hline Strategy & Examples \\
\hline Revenue generation & 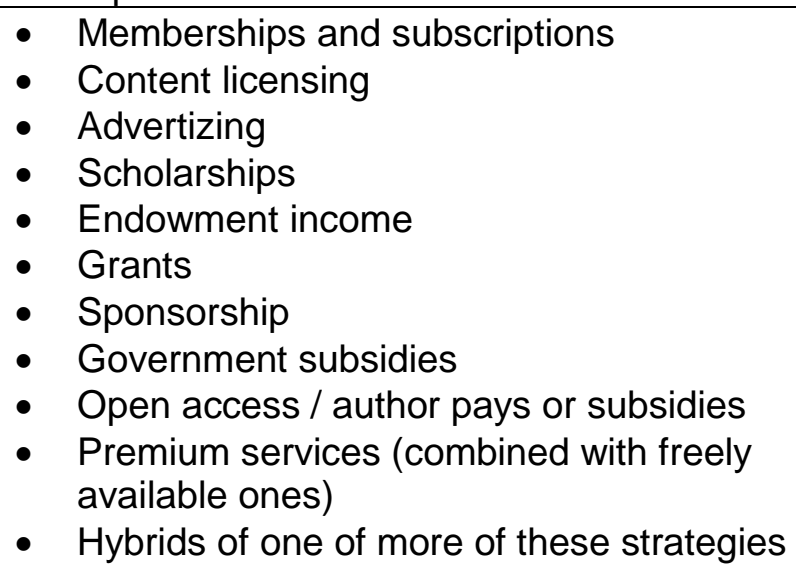 \\
\hline Nonfinancial support & $\begin{array}{l}\text { - Volunteer labor } \\
\text { - Partnerships (including public/private) } \\
\text { - Support from host institution } \\
\text { - Other in-kind contributions, e.g., free rent, } \\
\text { technical support, server space, } \\
\text { contributed staff time, non-billed overhead } \\
\text { costs }\end{array}$ \\
\hline Controlling and reducing costs & $\begin{array}{l}\text { - Outsourcing } \\
\text { - Sharing responsibility for some functions }\end{array}$ \\
\hline
\end{tabular}

The findings of the 2009 lthaka study centered on the following points:

- Digital library builders and managers are using a mix of funding strategies; no consensus has emerged around best practices for funding

- Virtually no initiatives earn enough revenue to survive without supplemental sources of funding

- In-kind contributions from host institutions are extremely important, and these are rarely quantified, leading to "fuzzy" accounting practices and an unclear picture of direct costs

- Controlling and reducing costs are as important as identifying diverse sources of revenue

- Open access to content can pose challenges to generating funds for cost recovery 


\section{Public-private partnerships}

With respect to the last bullet point above, Savenije and Beunen (2012) discusses public-private partnerships in the context of the tension between providing open access to content and achieving financial solvency. Such partnerships are a possibility, for example, when cultural heritage organizations are unable to raise the necessary funds for digitization. Savenije however points out the difficulties of insisting on open access to public domain content that was digitized by a private sector partner, who then has few options for recouping the investment it has made in scanning. Embargo periods, followed by open access to the content, have provided one way of dealing with this difficulty.

\section{Business planning}

In a paper prepared for the 2009 Nobel Symposium in Stockholm, Kevin Guthrie, president of Ithaka, offered some additional insights into the results of the Ithaka case studies $(2011,119$ 123):

- The ability to fund future development for maintaining value to users is unclear

- A number of teams lacked business expertise and entrepreneurial skills or were heavily dependent on one or two individuals for these skills

Mel Collier, Leuven University's chief librarian, has written and compiled a number of articles and case studies on business models and planning for sustaining digital libraries. In his overview essay, Collier lists the following planning questions for digital library builders and managers to explore $(2010,15)$ :

- What benefits will the digital library generate for its intended audience(s)?

- What is the unique selling point (the particular qualities that differentiate the digital library from alternatives)? 
- What is the target audience or audiences and what is its size?

- What are the enabling technologies?

- What are the risks?

- Who will fund the initiative now and over time, and how?

Collier introduces the elements of a business model (how a product, service or organization will generate income and/or cover costs). These include a statement of aims, vision and mission; what services are offered (or needs addressed); profile(s) of the target audience(s); nature of the enterprise (profit or nonprofit, public or private, self-sustaining, combination); and nature and sources of income.

Business plans are not the same as business models: plans contain a different set of elements, although some elements overlap with those of business models. The particular set of elements vary from source to source (a "how to" book for business planning in libraries is Harriman 2008, which includes sections describing the component parts of a business plan, 25 sample plans and a number of worksheets). Examples of digital library business plans can be hard to get (as they are often confidential); Collier's compilation (2010) includes numerous essays on the business planning aspects of digital libraries by sector (cultural heritage and higher education) and by type of content (e-journals, e-books, e-archives, web sites, repositories, etc.), as well as seven case studies.

\section{Uncertainty and resourcefulness}

Digital library builders and managers are often part of parent institutions that are already funding a traditional set of services, and digital library costs make new demands on an already stretched budget. It is not uncommon for an ongoing digital library program to be running on various 
sources of external funds or with funds scraped together from otherwise uncommitted institutional funds of one kind or another. In other words, digital library programs have often been funded at the margins of the organization's budget (see also the 2013 Ithaka study by Maron and Pickle). This is why digital library managers tend to learn how to be resourceful, from preparing grant proposals to being creative and entrepreneurial about funding strategies. It is also why digital library programs are increasingly creating pressure to restructure and reallocate budgets tied up in the provision of traditional library services-there is just not enough money to cover both the old services and the new initiatives. This pushes the search for sustainability in a number of new directions.

\section{We don't know yet}

The context in which digital library builders and managers are attempting to find successful models for sustainability is extremely challenging. Mike Lesk concluded a detailed examination of how to pay for digital libraries with the words "we don't know yet" $(2004,50)$. While a great deal has changed since Lesk completed his analysis in 2004, the digital library field's knowledge of how to build digital libraries continues to outpace its understanding of how to sustain them.

\section{Conclusion}

Online communities have life cycles from inception through creation, growth and maturity. The life cycle model can be used to examine what is likely to attract, grow and maintain a community around a digital library. It can also be used as a framework for providing insight into why some digital libraries are long-lived, while others fade into memory.

Successful digital libraries appear to have found the right mix of community engagement, quality collections, and technologies/methods supporting user-centered design, ease of use and reliable performance. A strong orientation to understanding the needs, goals and behaviors of 
the communities to be served appears to be a key success factor. The life cycle model suggests that at maturity, successful digital libraries are trusted sites that engage a number of participating subgroups (contributors and consumers of content, individuals interacting with each other, volunteers and partners playing various roles, etc.). Securing sustainable funding continues to be a difficult challenge for many digital libraries.

The next chapter applies the life cycle framework presented in this chapter to examine the prospects of open access repositories. 